\title{
Nicotine Addiction and Psychological Stress: a Case-control Study Among the Unemployed North Indians
}

\section{Anurag Mishra}

University of Allahabad Faculty of Science https://orcid.org/0000-0001-7063-0057

\section{Rishabh Kumar}

University of Allahabad Faculty of Science

\section{Satya Narayan Mishra}

Shambhunath Institute of Engineering and Technology

Sivakumar Vijayaraghavalu

Narayana Medical College and Hospital

Munish Kumar ( $\nabla$ munishkp@gmail.com )

University of Allahabad Faculty of Science

\section{Research Article}

Keywords: Nicotine, Psychological stress, Oxidative stress, MDA, SOD, Homocysteine

Posted Date: January 25th, 2022

DOI: https://doi.org/10.21203/rs.3.rs-1269770/v1

License: (9) This work is licensed under a Creative Commons Attribution 4.0 International License. Read Full License 


\section{Abstract}

Background: In India, nicotine addiction causes a huge socio-economic burden, mortality, and morbidity. Chronic intake develops a variety of symptoms and life-long medical complications. The study aims to examine the nicotine-induced effects on cellular oxidative stress and psychological stress and its correlations with homocysteine (Hcy) concentration in nicotine-addicted respondents.

Methods \& Results: Nicotine-induced psychological stress was assessed through perceived stress scales (PSS) and coping self-efficacy (CSE) scales and oxidative stress was estimated through the markersMalondialdehyde (MDA), superoxide dismutase (SOD), and Catalase. We found significantly higher $(p=0.0001)$ perceived stress (PS) with diminished CSE in addicted respondents whereas low PS with significantly increased $(p=0.0001)$ CSE were observed in non-addicted. In erythrocytes (RBCs), MDA content was found significantly increased $(p=0.0006)$ in the nicotine-addicted group that may cause oxidative damage. SOD activity was significantly decreased $(p=0.0001)$ in the addicted group. Similarly, plasma Catalase activity was also decreased $(p=0.02)$. Nicotine intake influences Hcy concentration, by $\mathbf{5 5} \%, \mathbf{2 7 . 5} \%$, and $\mathbf{7 . 5 \%}$ in addicted respondents categorized as moderate, intermediate, and severe Hcy categories.

Conclusions: The minimal short-term nicotine consumption has the antioxidant role that promotes positive stimulus on memory and triggers executive functions but the same gets impaired and mitigated on chronic exposure. Chronic nicotine consumption induces oxidative stress and perceived psychological stress as well as influences the Homocysteine concentration in the addicted individuals. Higher oxidative stress impairs cellular defensive mechanisms and causes the risk for severe damage to cells and tissues.

\section{Introduction}

Globally, India is the second-largest producer and consumer of tobacco (nicotine) or its related products. The most prevalent form of tobacco intake is Gutkha, Khaini, Zarda, Betel quid with tobacco, Bidi, Cigarette, and Hookah. According to the India Global Adult Tobacco Survey (2016-17), approximately 267 million adults above the age of 18 years (29\% of all adults) are addicted to tobacco. Tobacco consumption causes a huge socio-economic burden, mortality, and morbidity across the world. Nearly, 1.35 million deaths were reported in India and 8 million deaths worldwide annually. The estimated economic burden in the year (2017-2018) attributed through tobacco consumption, related diseases, and mortality in the Indian population was INR 1773.4 billion or US $\$ 27.5$ billion [1, 2]. The way of tobacco consumption among the rural and urban population and slum areas is diversely distributed [3]. Therefore, many policies have been constituted to manage and regulate tobacco consumption, advertising, economic burdens, and mortality in the country [4]. Despite all efforts, the ratio of tobacco consumption among unemployed youth has been raised [5]. Millions of educated adults are unemployed or under the threat of being jobless, many of them often use tobacco as a stress reliever [6, 7]. 
Nicotine is an addictive substance found in all tobacco products that cause poisonous effect and increase the risk for several non-communicable chronic diseases like heart disease, stroke, cancer, etc. [8]. Addiction has been identified as a brain disorder characterized by compulsive engagement in rewarding stimuli despite adverse consequences [9]. Addiction may strongly affect the way of feelings that can be euphoric and develop the tendency of its frequent use [10]. Despite the involvement of several psychosocial factors, repeated exposure to an addictive stimulus may be the core pathology to drive the development of addiction to nicotine. Resulting, neuroadaptation develops the number of binding sites on the nicotinic cholinergic receptors in the brain, probably due to the response of nicotine-mediated desensitization of binding receptors. Ligand-induced and unresponsiveness of the receptors play a vital role in nicotine tolerance and dependence; as shown in (Fig. 1) the symptoms of craving and withdrawal begin in smokers when desensitized receptors a $4 \beta 2$ nicotinic cholinergic become responsive during the periods of abstinence [11-13]. Chronic nicotine addiction induces psychological stress and oxidative stress; oxidative stress appears as significant biomarkers such as MDA (a product of lipid peroxidation), SOD, and Catalase. However, not much comprehensive research on nicotine's direct influence on MDA has yet been reported [14]. Several other plausible theories have arisen to explain nicotine's beneficial effects on oxidative stress as less nicotine consumption serves as a good antioxidant, scavenging the free radicals generated by monoamine oxidase- $B[15,16]$. Nicotine addiction may influence the Hcy metabolism and cause Hyperhomocysteinemia (Hhcy) and Homocystinuria. These (Hhcy/Homocystinuria) are the significant risk factor for causing several diseases such as cardiovascular disease (CVD), cerebrovascular disease, diabetes, hip fracture, cognitive decline, osteoporosis, chronic kidney disease, hypothyroidism, Alzheimer's disease, Parkinson's disease, and cancer [17-19]. In some studies, an adverse link between smoking and Hcy metabolic abnormalities has been reported [20]. Although much collaborative research work is required to explore the influence of nicotine and oxidative stress on Hcy metabolism yet.

The goal of the study is to examine the interaction of chronic nicotine consumption with cellular defensive enzymes, lipid peroxidation, and Hcy abnormalities in selected population groups. The study also focused to estimate perceived psychological stress and coping measures in the affected individuals.

\section{Materials \& Methods}

\section{Selection of Volunteers:}

This study was carried out on 156 healthy unemployed literate youth volunteers (age range; 20 to 40 years), randomly recruited in Prayagraj, Uttar Pradesh, India. All the participants were surveyed for nicotine (tobacco) addiction or consumption either smoking form (Bidi, Cigarette, and Hookah) or nonsmoking form (Gutkha, Khaini, Zarda, and Betel quid with tobacco). The enrolled participants were divided into two groups viz., 1. Control: never consumed nicotine; 2 . Cases: consumed nicotine at least (4 times/day) in any of the available forms for two years before their enrollment. All the study participants (cases and controls) were screened through a pre-listed health history questionnaire for any medical complications such as Diabetes, Asthma, CVD, Depression, Anxiety, and other mental disorders. The 
inclusion criteria also ensured that volunteers were not on any medication regime. The study objective was clearly explained to the volunteers and their consent was taken to prior recruiting in the study.

This study has been approved by the population resource and research center, institutional ethics committee, Praygaraj, UP, India, with reference number IERB19/9.42.

\section{Anthropometric Measures:}

For anthropometric measurements, the body weight in kilogram $(\mathrm{kg})$, and height in centimeter $(\mathrm{cm})$ of all the volunteers were measured. Body mass index $\left(\mathrm{BMI}, \mathrm{kg} / \mathrm{m}^{2}\right)$ was calculated. BMI values in the range of 18 to 25 were considered normal; 25 to 30 - overweight; $>30$ as obese class I, II, and III $(30-35,35-40,>40$ respectively) [21].

\section{Blood Sample Collection, Storage, and Processing:}

Blood samples were collected from the enrolled subjects (both non-addicted and nicotine-addicted) at the registered pathology center by a well-experienced pathologist in two different vials - 1. EDTA vials for plasma and RBCs separations, 2. Plain vials for serum separation. RBCs, plasma, and serum were separated at $4{ }^{\circ} \mathrm{C}$ temperature, collected in required volume, and frozen at minus $80^{\circ} \mathrm{C}$ temperature for further use [22].

\section{Preparation of Hemolysate:}

Hemolysate was prepared by the destruction of packed RBCs and release of its content like hemoglobin and others. A $20 \mu \mathrm{L} \mathrm{RBCs}$ was taken out and washed with $0.9 \% \mathrm{NaCl}$ solution $2-3$ times repeatedly, centrifuged at $3000 \mathrm{rpm}$ (revolution per minute) for $5 \mathrm{~min}$, supernatant was discarded and pellets were obtained carefully. A $380 \mu \mathrm{L}$ of stabilizing solution was added to it and kept the final volume $400 \mu \mathrm{L}$. It was stored at $-80^{\circ} \mathrm{C}$ for the estimation of MDA and SOD [23].

\section{Biochemical Measures}

\section{Estimation of Hemoglobin:}

Hemoglobin concentration was measured in all blood samples by Drabkin's method. A standard hemoglobin solution was used for calibration. The absorbance was measured in a UV-Vis double beam spectrophotometer at $540 \mathrm{~nm}$ [24].

\section{Estimation of Plasma Protein:}

Measurement of protein quantity in each plasma sample was done by the Folin-Lowry method. A standard protein solution of Bovine Serum Albumin (BSA) was used to calibrate. Absorbance was recorded in UV-Vis double beam spectrophotometer at $660 \mathrm{~nm}$ wavelength [25].

\section{Estimation of Homocysteine:}


Plasma Hcy levels were measured in all samples by employing a method given by Pfeiffer et al., 1999 with minor modification [26]. This estimation was performed on high-performance liquid chromatography (HPLC). Various chemicals, standard solutions, and reagents were used. Hcy concentrations are expressed as $\mu \mathrm{mol} / \mathrm{L}$, the concentrations between 5 to $15 \mu \mathrm{mol} / \mathrm{L}$ are considered to be normal, and $>15$ $\mu \mathrm{mol} / \mathrm{L}$ is considered to be elevated in the body's fluids.

\section{Estimation of lipid peroxidation product (MDA) in RBCs:}

Erythrocyte's MDA was measured with a slight modification of the method given by Senthilkumar et al., 2021. MDA was considered as an index for lipid peroxidation. For estimation, hemolysate was mixed with $0.2 \mathrm{M}$ phosphate buffer ( $\mathrm{pH}$ 7.4) and TBA-TCA-HCl reagents. Incubated in boiling water bath for $30 \mathrm{~min}$ at $100^{\circ} \mathrm{C}$, and then centrifuged to obtain clear supernatant. The absorbance of the supernatant was measured in UV-Vis double beam spectrophotometer at $532 \mathrm{~nm}$ wavelength. The MDA content was calculated by using extinction coefficient $(\nabla=156,000)$ and expressed as $\mathrm{nmol} / \mathrm{g}$ of $\mathrm{Hb}$ or $\mathrm{nmol} / \mathrm{mL}$ of RBCs [27].

\section{Estimation of MDA in Plasma:}

Plasma MDA was measured as the same method employed for erythrocyte's MDA estimation.

\section{Estimation of Superoxide Dismutase (SOD):}

Erythrocyte's SOD was measured with a slight modification of the method given by Marklund \& Marklund, 1974. Tris-succinate buffer ( $\mathrm{pH}$ 8.2) and Pyrogallol (light-sensitive) are used for the estimation of SOD activity in RBCs. The blank tube constituted only $3 \mathrm{~mL}$ of tris-succinate buffer whereas the reference tube constituted the solution mixture $(2.9 \mathrm{~mL}$ buffer $+50 \mu \mathrm{L}$ distilled water $+100 \mu \mathrm{L}$ Pyrogallol $)$ and in the sample solution mixture $(2.9 \mathrm{~mL}$ buffer $+50 \mu \mathrm{L}$ hemolysate $+100 \mu \mathrm{L}$ Pyrogallol). Absorbance was recorded in a UV-Vis double beam spectrophotometer at $420 \mathrm{~nm}$ for $4 \mathrm{~min}$ at the interval of 30 seconds. The catalytic activity of SOD was expressed as (nmol/min/g of $\mathrm{Hb}$ ) [28].

\section{Estimation of Catalase:}

The plasma Catalase activity was measured as described by Sinha 1972 with slight modification. A $0.01 \mathrm{M}$ phosphate buffer $(\mathrm{pH} 7)$ was used to make the dilution of $\mathrm{H}_{2} \mathrm{O}_{2}$. As for the blank solution, $2.5 \mathrm{~mL}$ of unitary phosphate buffer (PB) solution was used while a solution mixture $(1.45 \mathrm{~mL}$ of $\mathrm{PB}+50 \mu \mathrm{L}$ of $\mathrm{H}_{2} \mathrm{O}+1 \mathrm{~mL}$ of diluted $\left.\mathrm{H}_{2} \mathrm{O}_{2}\right)$ was taken as a reference analytes, and in the test sample $(1.45 \mathrm{~mL}$ of $\mathrm{PB}+$ $50 \mu \mathrm{L}$ of plasma sample $+1 \mathrm{~mL}$ of diluted $\mathrm{H}_{2} \mathrm{O}_{2}$ ) was used. Absorbance was recorded at $240 \mathrm{~nm}$ wavelength for 3 min at the interval of 30 seconds. Due to the activity of $\mathrm{H}_{2} \mathrm{O}_{2}$ with the test sample mixture, the absorbance was recorded decreased with time. Catalase activity was expressed as IU (International Unit; denotes one unit decomposes $1 \mu$ mole of $\mathrm{H}_{2} \mathrm{O}_{2}$ per min at $\mathrm{pH}-7$ and $25^{\circ} \mathrm{C}$ ) [29].

\section{Psychological Assessment}




\section{Perceived Stress (PS):}

PSS is one of the validated and widely accepted instruments used for psychological assessment. In general, it measures the degree to which situations in one s life is appraised as stressful. A questionnaire of 10 items based on the frequency of emotional feelings and thoughts during the past month was given to volunteers and asked them to respond. According to the overall individual's score, all volunteers were categorized into three stress categories as low stress ( $<13)$, moderate stress (14-26), and high stress (2740) [30].

\section{Coping Self-Efficacy (CSF):}

CSE scale is one of the validated and standardized lists of 26 items given by (Chesney et al., 2006) used to assess someone's coping efficacy against life's challenges and threats when the conditions aren't going well, or are difficult. All volunteers were asked for rating each item (0 to 10$)$ carefully according to their existing perceived self-efficacy. The entire rating points for each item have been categorized as 0 points $=$ cannot do all, 1 to 5 points $=$ moderately can do and 6 to 10 points $=$ certain can do [31].

\section{Statistical Analysis of Data}

The statistical data processing of the results was carried out by using Microsoft excel 2019 and GraphPad prism version 9 program. Pearson's correlation coefficient was also calculated among the groups. The result has been presented as the mean and standard error of the mean (SEM). The statistical significance of the difference was verified using the t-test at $95 \%$ confidence and $p$-value at $(p<0.05)$. The comparisons were made between the socio-demographic, clinical, and laboratory measurements, using appropriate parametric tests where data were normally distributed.

\section{Results}

\section{Anthropometric comparison}

Non-addicted and nicotine-addicted respondents were enrolled and assessed individually by their age, height, weight, and BMI, and the addiction history was recorded. As shown in (Table 1), the two groups were matched for age, height, weight, and BMI. 
Table 1

Age and anthropometric measures of enrolled volunteers

\begin{tabular}{|llccc|}
\hline Anthropometric measures & \multicolumn{3}{l}{$\begin{array}{l}\text { Non-addicted males (control) } \\
\mathrm{n}=\mathbf{7 6}\end{array}$} & $\begin{array}{l}\text { Addicted males (cases) } \\
\mathrm{n}=\mathbf{8 0}\end{array}$ \\
\hline Age (years) & 22.92 & \pm 0.30 & 24.00 & \pm 0.54 \\
\hline Height $(\mathrm{m})$ & 01.67 & \pm 0.007 & 01.65 & \pm 0.007 \\
\hline Weight $(\mathrm{kg})$ & 59.16 & \pm 0.86 & 59.60 & \pm 1.05 \\
\hline BMl & 21.27 & \pm 0.26 & 21.73 & \pm 0.28 \\
\hline Table1: All values are expressed as Mean and \pm SEM (standard error of the mean) \\
\hline
\end{tabular}

\section{Effect on perceived psychological stress}

Enrolled volunteers were divided into three stress categories Low, Moderate, and High corresponding to the ranges- $0-13,14-26$, and $27-40$ on the PS scale. As represented in (Table 2 \& Supplementary Fig. 1 ) the non-addicted volunteers were grouped either in the low or moderate PS category whereas in the addicted group only $\mathbf{5 \%}$ show low stress, over half $(\mathbf{6 0 \%})$ show moderate, and a fairly $\mathbf{3 5 \%}$ proportion show high perceived stress. Observations indicate nicotine influence perceived stress level in addicted.

Table 2

The proportions of non-addicted and nicotine-addicted respondents in low, moderate, and high PS categories

\begin{tabular}{|c|c|c|c|}
\hline $\begin{array}{l}\text { PS } \\
\text { Category }\end{array}$ & Range of scores & $\begin{array}{l}\text { Non-addicted males (control) } \\
\mathrm{n}=76\end{array}$ & $\begin{array}{l}\text { Addicted males (cases) } \\
\mathrm{n}=80\end{array}$ \\
\hline Low & $0-13$ & $(55.27 \%)$ & $(05 \%)$ \\
\hline Moderate & $14-26$ & $(44.73 \%)$ & $(60 \%)$ \\
\hline High & $27-40$ & $(00.00 \%)$ & $(35 \%)$ \\
\hline
\end{tabular}

\section{Effect on Homocysteine concentration}

As given in (Table 3 \& Supplementary Fig. 2), approximately $\mathbf{5 5 \%}$ of nicotine-addicted express moderate, $\mathbf{2 7 . 5}$ express intermediate, and $\mathbf{7 . 5 \%}$ express severe Hcy concentration whereas, in the non-addicted, nearly $\mathbf{5 5 . 3 \%}$ volunteers were placed in low, $\mathbf{3 6 . 8 \%}$ in moderate, and $\mathbf{7 . 8 \%}$ in intermediate Hcy categories respectively, 
Table 3

Measurements of Homocysteine level in the blood plasma of non-addicted and nicotine-addicted respondents

\begin{tabular}{|lllll|}
\hline $\begin{array}{l}\text { Homocysteine Measures } \\
\text { (in Plasma) }\end{array}$ & \multicolumn{2}{l}{$\begin{array}{l}\text { Non-addicted males (control) } \\
\mathrm{n}=76\end{array}$} & \multicolumn{3}{l|}{$\begin{array}{l}\text { Addicted males (cases) } \\
\mathrm{n}=80\end{array}$} \\
\hline Low $(<16 \mu \mathrm{mol} / \mathrm{L})$ & 42 & $(55.26 \%)$ & 08 & $(10.00 \%)$ \\
\hline Moderate $(16$ to $30 \mu \mathrm{mol} / \mathrm{L})$ & 28 & $(36.84 \%)$ & 44 & $(55.00 \%)$ \\
\hline Intermediate $(31$ to $100 \mu \mathrm{mol} / \mathrm{L})$ & 06 & $(07.80 \%)$ & 22 & $(27.50 \%)$ \\
\hline Severe $(>100 \mu \mathrm{mol} / \mathrm{L})$ & 00 & $(00.00 \%)$ & 06 & $(07.50 \%)$ \\
\hline \multicolumn{4}{|l}{ Table 3: Values in parenthesis represent the value of the cell as a percent of the total $\mathrm{n}$ of the column. } \\
\hline
\end{tabular}

\section{PS and CSE relation}

As represented in (Table 4), a significantly higher PS was found in the nicotine-addicted group $(p=0.0001)$. Contrarily the nicotine-addicted group expressed significantly lower/reduced CSE than the non-addicted ( $p=0.0001)$. The data of significant differences between the groups for PS and CSE has been depicted in (Fig. 2 \& 3). 
Table 4

Data of Psychological stress measures and Oxidative stress measures in non-addicted and nicotineaddicted groups with their respective p-values

\begin{tabular}{|c|c|c|c|c|c|}
\hline \multirow[t]{2}{*}{ Measures } & \multicolumn{2}{|c|}{$\begin{array}{l}\text { Non-addicted males } \\
\text { (control) }\end{array}$} & \multicolumn{2}{|c|}{$\begin{array}{l}\text { Addicted males } \\
\text { (cases) }\end{array}$} & \multirow[t]{2}{*}{$\begin{array}{l}\text { p-value at } \\
(<0.05)\end{array}$} \\
\hline & \multicolumn{2}{|l|}{$n=76$} & \multicolumn{2}{|l|}{$\mathrm{n}=80$} & \\
\hline \multicolumn{6}{|l|}{ Psychological Stress Measures } \\
\hline PS Scores & 15.05 & \pm 0.58 & 21.75 & \pm 0.53 & $0.0001 * * *$ \\
\hline CSE Scores & 180.37 & \pm 4.36 & 154.85 & \pm 3.47 & $0.0001 * * *$ \\
\hline \multicolumn{6}{|l|}{ Oxidative Stress Measures } \\
\hline MDA in RBCs $(\mathrm{nmol} / \mathrm{g}$ of $\mathrm{Hb})$ & 0.197 & \pm 0.007 & 0.229 & \pm 0.006 & $0.0006 * * *$ \\
\hline & & $\cdot$ & & & \\
\hline $\begin{array}{l}\text { MDA in Plasma (nmol/mL of } \\
\text { Protein) }\end{array}$ & 0.183 & \pm 0.01 & 0.183 & \pm 0.007 & 1.0000 \\
\hline \multicolumn{6}{|l|}{$\begin{array}{l}\text { Antioxidant Enzyme's Activity } \\
\text { Measures }\end{array}$} \\
\hline $\begin{array}{l}\text { SOD in RBCs }(\mathrm{nmol} / \mathrm{min} / \mathrm{g} \text { of } \\
\mathrm{Hb})\end{array}$ & 0.221 & \pm 0.006 & 0.172 & \pm 0.004 & $0.0001 * * *$ \\
\hline Plasma Catalase (IU) & 0.289 & \pm 0.06 & 0.121 & \pm 0.04 & $0.02 *$ \\
\hline
\end{tabular}

\section{Effect on MDA and Cellular defensive mechanism}

From (Table 4), we measured significantly increased MDA (0.229 \pm 0.006$)$ content in the RBCs of the nicotine-addicted group ( $p=0.0006$ ), and the comparison has been shown in (Fig. 4.a). A significantly decreased $(0.172 \pm 0.004)$ SOD activity in the RBCs of the addicted group ( $p=0.0001)$ was measured and comparisons have been shown in (Fig. 4.b).

Similarly, plasma Catalase activity was also found significantly decreased $(0.121 \pm 0.04)$ in the addicted respondents $(\mathbf{p}=\mathbf{0 . 0 2})$ and its comparison has been depicted in (Fig. 5).

\section{Discussion}

Nicotine addiction is extensively employed as a stress reliever in today's contemporary lifestyle but longterm consumption may be hazardous for physical and mental health [32]. This may also affect brain 
activity, producing neurodegenerative illnesses and degrading the nervous system's potential [33]. In the survey, we observed that nicotine users often report that their consumption helps to relieve the feeling of stress, divert the way of thinking and improve work performance. However, the stress levels of adult tobacco users have been seen adversely higher than non-tobacco users [34]. As given the possible involvement of nicotine addiction in oxidative stress, the goal of this study was to look into the long-term effects of nicotine on psychological stress and Hcy metabolism. We primarily attempted to examine the interaction of nicotine addiction on perceived stress, perceived coping efficacy, oxidative stress markers (MDA, SOD, and Catalase); and then observed its correlation with Hcy concentration among enrolled volunteers. PS is adversely associated with coping efficacy in the whole addicted group which supports hypothesis and consistency with the findings [35]. Individuals' coping strategy under stressful situations was seen lower in the nicotine-addicted group. Researchers have also explored a negative correlation between PS and CSE, implying that coping efficacy worsens with greater perceived stress [36]. Several previous studies focused on nicotine addiction that promotes oxidative stress both in vivo and in vitro which causes peroxide/antioxidant imbalance in blood cells, blood plasma, and tissues [37]. Concomitant to a study [38], we also found nicotine addiction substantially stimulates MDA levels in the current study. Significantly higher MDA content was detected in RBCs of the addicted group, although the same has not been found consistently in plasma samples. Higher MDA content in the RBCs reveals an important clue for oxidative damage in the nicotine-addicted respondents [39]. SOD is a well-known primary antioxidant enzyme that counteracts superoxide radicals produced in the cells, serves as a powerful defensive system of cells [40]. The steady-state concentration of superoxide radicals in blood tissue may fluctuate directly with the rate of superoxide synthesis and inversely with the body's tissue concentration of scavenging enzymes [41]. We examined the effect of nicotine on the activity of SOD and Catalase, SOD activity was shown to be substantially decreased in the RBCs of nicotine-addicted than non-addicted and similar findings were also noted down for the plasma Catalase of nicotine-addicted group. These measurements suggest that the non-addicted respondents have developed the good potential to defend effectively against oxidative damage [42].

Apart from other defects of nicotine addictions it also affects the way of Hcy metabolism either the remethylation pathway or transsulfuration pathway, elevating Hcy concentration in the addicted respondents [43]. We found, about $55.0 \%, 27.5 \%$, and $7.5 \%$ of nicotine-addicted respondents are suffering from moderate, intermediate, and severe Hcy levels respectively. Nicotine addiction and oxidative stress are found linked to the defective process of Hcy metabolism, elevating Hcy concentration in the body [44]. Elevated Hcy may act as an independent risk factor for a variety of diseases/disorders like Osteoporosis, Hip fracture, Cognitive decline, Diabetes, CVD, Chronic kidney disorder, Hypothyroidism, Alzheimer's, Parkinson's, Cancer, etc. $[45,46]$. However, much comprehensive and collaborative research is required to explore the association of nicotine and oxidative stress on Hcy metabolism yet [47]. To control tobacco consumption and other associated burdens many effective and aggressive anti-tobacco campaigns are needed to promote awareness of its harm. A well-planned strategy is very essentials to provide jobs/works to needy individuals and to manage unemployment in society. Because recent data highlights 
that illiteracy and unemployment are the two significant factors for nicotine consumption among the youth population.

\section{Declarations}

\section{Funding Information:}

"The authors declare that no funds, grants, or other financial support were received during the research work and manuscript preparation."

\section{Competing Interests:}

"The authors have no any relevant financial or non-financial interests to disclose."

\section{Conflict of Interests:}

"The authors declared no potential conflicts of interest concerning the research, authorship, and/or publication of this article."

\section{Author Contributions:}

All authors listed on the title page have contributed to the study's conception and design. Material preparation, sample collection, and data analysis were nicely performed by Anurag Mishra, Satya Narayan Mishra, Rishabh Kumar, and Dr. Munish Kumar. The first draft of the manuscript was written by Anurag Mishra and all authors commented on previous versions of the manuscript. All authors have read and approved the final manuscript.

\section{Data Availability Statements:}

"The data that support the findings of this study are available from the corresponding author upon reasonable request."

\section{Ethics Approval:}

"The study has been approved by the population resource and research center, institutional ethics committee, Prayagraj, UP, India, with reference number IERB19/9.42."

\section{Consent to Participate:}

"Informed consent was obtained from all individual participants included in the study."

\section{Acknowledgments:}

We would like thank to all participants for their kind support during the study. We also thank to the University of Allahabad for providing all the basic infrastructure and facilities to carry out the study. 


\section{References}

1. About Global Adult Tobacco Survey 2, India 2016-17 (2018) - Research Project. https://www.tiss.edu/view/11/research-projects/global-adult-tobacco-survey-round-2-for-india-2016

2. Tobacco December 29, (2021). https://www.who.int/news-room/fact-sheets/detail/tobacco

3. Gupta V, Yadav K, Anand K (2010). Patterns of tobacco use across rural, urban, and urban-slum populations in a north Indian community. Indian J Community Med 35:245-251. doi:10.4103/09700218.66877

4. National Tobacco Control Programme (NTCP) | Ministry of Health and Family Welfare | GOI (2021). https://main.mohfw.gov.in/major-programmes/other-national-health-programmes/national-tobaccocontrol-programme-ntcp

5. Grover S, Anand T, Kishore J, Tripathy JP, Sinha DN (2020). Tobacco Use Among the Youth in India: Evidence From Global Adult Tobacco Survey-2 (2016-2017). Tob Use Insights.

13:1179173X20927397. doi:10.1177/1179173X20927397

6. Hobkirk AL, Krebs NM, Muscat JE (2018) Income as a moderator of psychological stress and nicotine dependence among adult smokers. Addict Behav. 84:215-223.

doi:10.1016/j.addbeh.2018.04.021

7. India Unemployment Rate 1991-2021 (2021)

https://www.macrotrends.net/countries/IND/india/unemployment-rate

8. Centers for Disease Control and Prevention (US), National Center for Chronic Disease Prevention and Health Promotion (US), Office on Smoking and Health (US). How Tobacco Smoke Causes Disease: The Biology and Behavioral Basis for Smoking-Attributable Disease: A Report of the Surgeon General (2010) Centers for Disease Control and Prevention (US).

http://www.ncbi.nlm.nih.gov/books/NBK53017/

9. Grant JE, Potenza MN, Weinstein A, Gorelick DA (2010) Introduction to behavioral addictions. Am J Drug Alcohol Abuse. 36:233-241. doi:10.3109/00952990.2010.491884

10. Substance Abuse and Mental Health Services Administration (US), Office of the Surgeon General (US). Facing Addiction in America: The Surgeon General's Report on Alcohol, Drugs, and Health (2016) US Department of Health and Human Services.

http://www.ncbi.nIm.nih.gov/books/NBK424857/

11. Benowitz NL (2010) Nicotine addiction. N Engl J Med. 362:2295-2303. doi:10.1056/NEJMra0809890

12. Kuhn BN, Kalivas PW, Bobadilla AC (2019) Understanding Addiction Using Animal Models. Front Behav Neurosci. 13:262. doi:10.3389/fnbeh.2019.00262

13. Warner DO (2006) Perioperative abstinence from cigarettes: physiologic and clinical consequences. Anesthesiology. 104:356-367. doi:10.1097/00000542-200602000-00023

14. Hu JP, Zhao XP, Ma XZ, Wang Y, Zheng LJ (2014) Effects of cigarette smoke on aerobic capacity and serum MDA content and SOD activity of animal. Int J Clin Exp Med. 7:4461-4465. 
15. Barreto GE, larkov A, Moran VE (2014) Beneficial effects of nicotine, cotinine and its metabolites as potential agents for Parkinson's disease. Front Aging Neurosci. 6:340. doi:10.3389/fnagi.2014.00340

16. Newman MB, Arendash GW, Shytle RD, Bickford PC, Tighe T, Sanberg PR (2002) Nicotine's oxidative and antioxidant properties in CNS. Life Sci. 71:2807-2820. doi:10.1016/s0024-3205(02)02135-5

17. Al Mutairi F (2020) Hyperhomocysteinemia: Clinical Insights. J Cent Nerv Syst Dis. 12:1179573520962230. doi:10.1177/1179573520962230

18. Maron BA, Loscalzo J (2009) The treatment of hyperhomocysteinemia. Annu Rev Med. 60:39-54. doi:10.1146/annurev.med.60.041807.123308

19. Stipanuk MH (2020) Metabolism of Sulfur-Containing Amino Acids: How the Body Copes with Excess Methionine, Cysteine, and Sulfide. J Nutr. 150:2494S-2505S. doi:10.1093/jn/nxaa094

20. Sobczak AJ (2003) The effects of tobacco smoke on the homocysteine level-a risk factor of atherosclerosis. Addict Biol. 8:147-158. doi:10.1080/13556210310001117374

21. Nuttall FQ (2015) Body Mass Index: Obesity, BMI, and Health: A Critical Review. Nutr Today 50:117128. doi:10.1097/NT.0000000000000092

22. Lei BUW, Prow TW (2019) A review of microsampling techniques and their social impact. Biomed Microdevices 21:81. doi:10.1007/s10544-019-0412-y

23. Huntsman RG (1974) Red Blood Cell Hemolysate Preparation. CRC Critical Reviews in Clinical Laboratory Sciences 5:34-36. doi:10.3109/10408367409107621

24. 4. Analytical methods (1982) Scandinavian Journal of Clinical and Laboratory Investigation 42:3865. doi:10.1080/00365518209168385

25. Waterborg JH, Matthews HR (1984) The lowry method for protein quantitation. Methods Mol Biol. 1:1-3. doi:10.1385/0-89603-062-8:1

26. Pfeiffer CM, Huff DL, Gunter EW (1999) Rapid and accurate HPLC assay for plasma total homocysteine and cysteine in a clinical laboratory setting. Clin Chem. 45:290-292

27. Senthilkumar M, Amaresan N, Sankaranarayanan A (2021) Estimation of Malondialdehyde (MDA) by Thiobarbituric Acid (TBA) Assay. Springer Protocols Handbooks. Springer US 103-105. doi:10.1007/978-1-0716-1080-0_25

28. Marklund S, Marklund G (1974) Involvement of the superoxide anion radical in the autoxidation of pyrogallol and a convenient assay for superoxide dismutase. Eur J Biochem. 47:469-474. doi:10.1111/j.1432-1033.1974.tb03714.x

29. Sinha AK (1972) Colorimetric assay of catalase. Anal Biochem. 47:389-394. doi:10.1016/00032697(72)90132-7

30. Cohen S, Kamarck T, Mermelstein R (1983) A global measure of perceived stress. J Health Soc Behav. 24:385-396

31. Chesney MA, Neilands TB, Chambers DB, Taylor JM, Folkman S. A (2006) validity and reliability study of the coping self-efficacy scale. Br J Health Psychol. 11:421-437.

doi:10.1348/135910705X53155 
32. Abuse NI on D (2021) Is nicotine addictive? National Institute on Drug Abuse. https://www.drugabuse.gov/publications/research-reports/tobacco-nicotine-e-cigarettes/nicotineaddictive

33. Hajdusianek W, Żórawik A, Waliszewska-Prosół M, Poręba R, Gać P (2021) Tobacco and Nervous System Development and Function-New Findings 2015-2020. Brain Sci. 11:797. doi:10.3390/brainsci11060797

34. Parrott AC (1999) Does cigarette smoking cause stress? Am Psychol. 54:817-820. doi:10.1037//0003-066x.54.10.817

35. Lee J, Kim E, Wachholtz A (2016) The effect of perceived stress on life satisfaction: The mediating effect of self-efficacy. Chongsonyonhak Yongu 23:29-47. doi:10.21509/KJYS.2016.10.23.10.29

36. Rauvat S, Dwivedi A, Mittal P (2020) Effect of nicotine abuse on oxidative stress and perceived stress and its relationship with coping self efficacy among university graduates. Journal of Experimental Biology and Agricultural Sciences 8:849-858. doi:10.18006/2020.8 (6).849.858

37. Kostelli G, Kourea K, Ikonomidis I (2020) Effects of combustible tobacco smoking and novel tobacco products on oxidative stress: Different sides of the same coin? Current Opinion in Toxicology 2021:41-47. doi:10.1016/j.cotox.2020.05.001

38. Jaggi S, Yadav AS (2015) Increased serum malondialdehyde levels among cigarette smokers. The Parma Innovation 4.4:94

39. Karajibani M, Montazerifar F, Khazaei Feizabad A (2017) Study of Oxidants and Antioxidants in Addicts. Int J High Risk Behav Addict. 6. doi:10.5812/ijhrba.35057

40. He L, He T, Farrar S, Ji L, Liu T, Ma X (2017) Antioxidants Maintain Cellular Redox Homeostasis by Elimination of Reactive Oxygen Species. Cell Physiol Biochem. 44:532-553. doi: 10.1159/000485089

41. Krumova K, Cosa G (2016) Chapter 1 Overview of Reactive Oxygen Species. Published online:1-21. doi:10.1039/9781782622208-00001

42. Agarwal P, Bagewadi A, Keluskar V, Vinuth DP (2019) Superoxide dismutase, glutathione peroxidase, and catalase antioxidant enzymes in chronic tobacco smokers and chewers: A case-control study. Indian J Dent Res. 30:219-225. doi:10.4103/ijdr.IJDR_268_12

43. Singh D (2016) Effect of Cigarette Smoking on Serum Homocysteine and Vitamin B12 Level in Male Population of Udaipur. Biochem Anal Biochem 5. doi:10.4172/2161-1009.1000282

44. Chen S, Wu P, Zhou L, Shen Y, Li Y, Song H (2015) Relationship between increase of serum homocysteine caused by smoking and oxidative damage in elderly patients with cardiovascular disease. Int J Clin Exp Med 8:4446-4454

45. Azzini E, Ruggeri S, Polito A (2020) Homocysteine: Its Possible Emerging Role in At-Risk Population Groups. Int J Mol Sci 21 E1421. doi:10.3390/ijms21041421

46. Tinelli C, Di Pino A, Ficulle E, Marcelli S, Feligioni M (2019) Hyperhomocysteinemia as a Risk Factor and Potential Nutraceutical Target for Certain Pathologies. Front Nutr 6:49.

doi:10.3389/fnut.2019.00049

Page 14/19 
47. Haj Mouhamed D, Ezzaher A, Neffati F, Douki W, Najjar MF (2011) Effect of cigarette smoking on plasma homocysteine concentrations. Clin Chem Lab Med 49:479-483. doi:10.1515/CCLM.2011.062

\section{Figures}

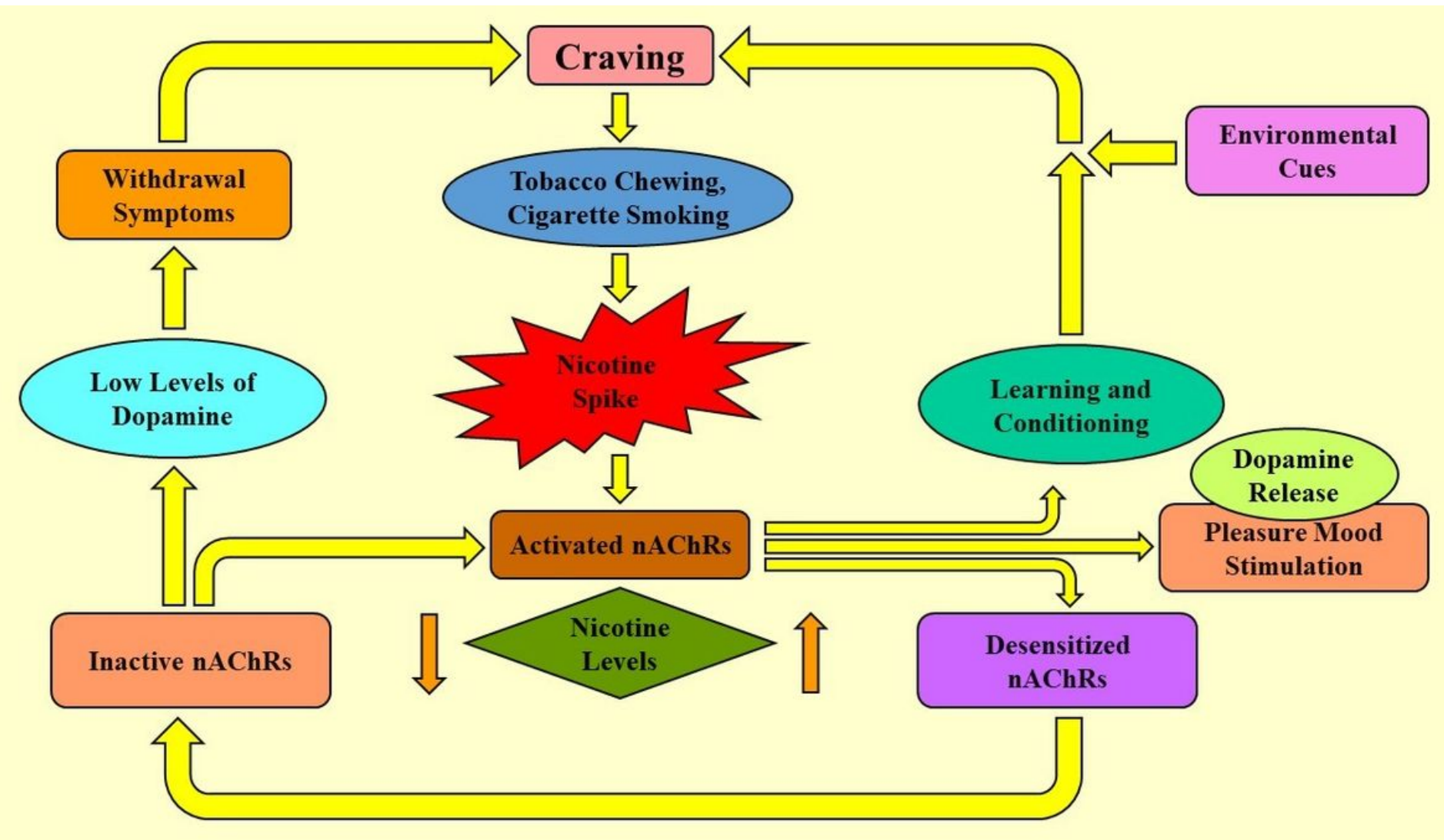

\section{Figure 1}

Schematic diagram of the mechanism of nicotine action; the symptoms of craving and withdrawal begin in smokers when desensitized receptors nicotinic cholinergic become responsive during the periods of abstinence. Structurally, nicotine is similar to acetylcholine (Ach) that is an important class of neurotransmitters involved in systems concerned with physical and mental arousal, learning memory, and several aspects of emotions. Ach receptors are traditionally classified as nicotine receptors and muscarine receptors. Primarily, nicotine stimulates the central nicotinic cholinergic receptors inducing the release of several neurotransmitters in the brain like dopamine, norepinephrine, serotonin, $y$-aminobutyric acid (GABA), etc. these lead to arousal, mood modulation, performance enhancement, analgesic, and weight-loss effects. 


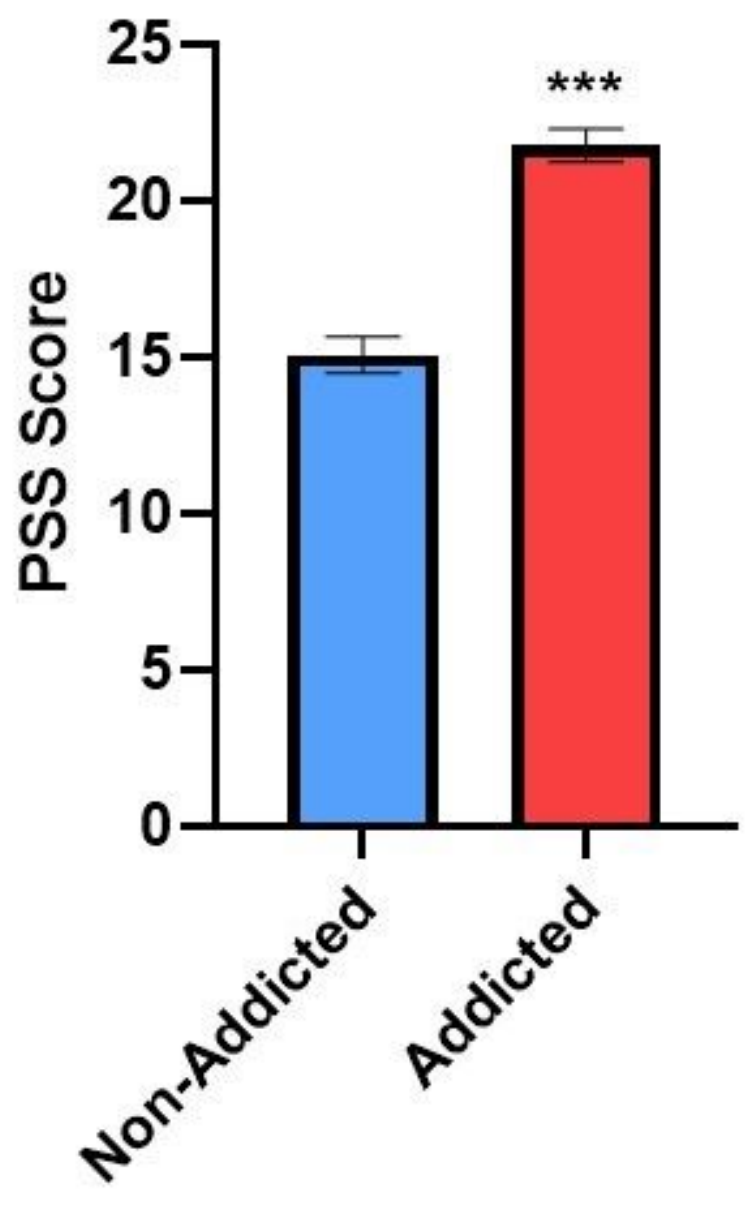

$\square$ Non-Addicted

$\square$ Addicted

\section{Figure 2}

The PS scores of addicted and non-addicted were calculated and expressed as the mean and standard error of the mean $( \pm S E M)$, and differences were obtained at $(p<0.05)$. Due to the effects of nicotine addiction, we have observed higher PS scores in nicotine-addicted respondents, and the differences were found statistically significant $(\mathrm{p}=0.0001)$. 


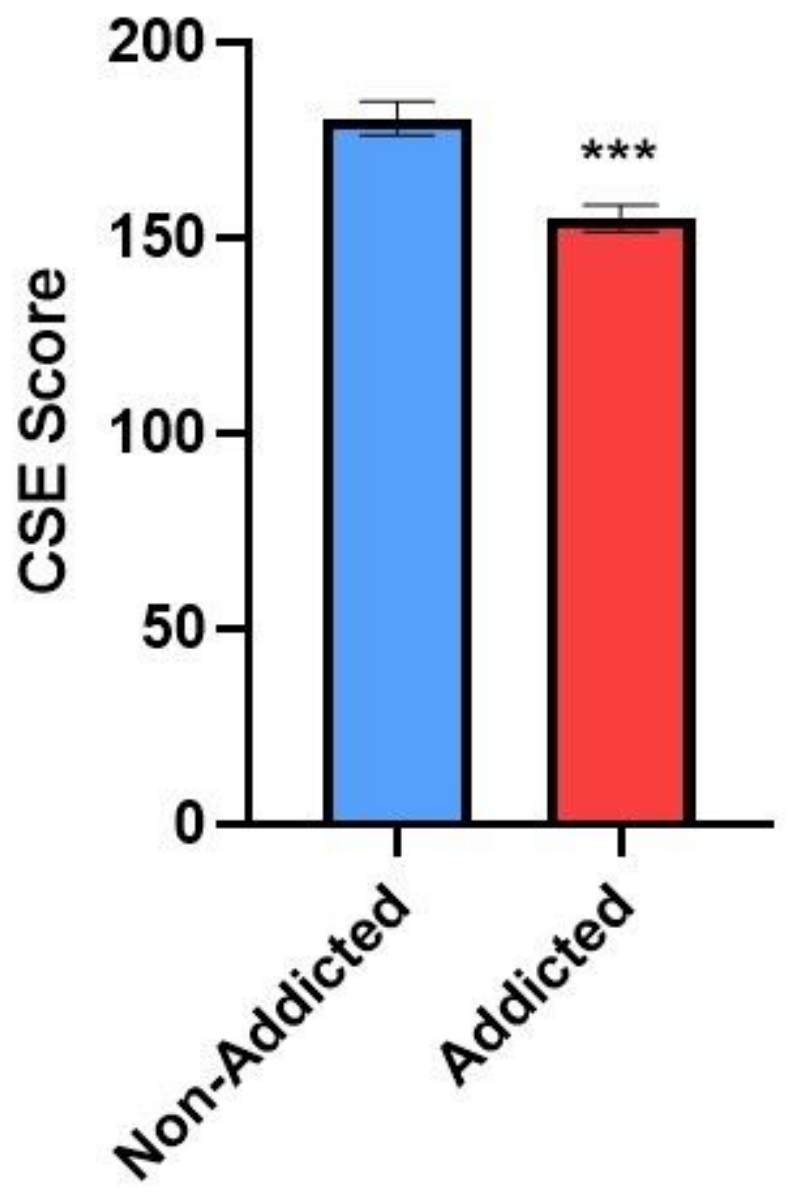

$\square$ Non-Addicted

$\square$ Addicted

Figure 3

Distribution in CSE scores; the non-addicted respondents showed a higher value of CSE than addicted; thus differences $(\mathbf{p}=\mathbf{0 . 0 0 0 1})$ were found statistically significant at $(\mathbf{p}<0.05)$. Low/poor CSE in the addicted indicates that these are unable to develop powerful coping strategies at the time of life's challenges and threats. 


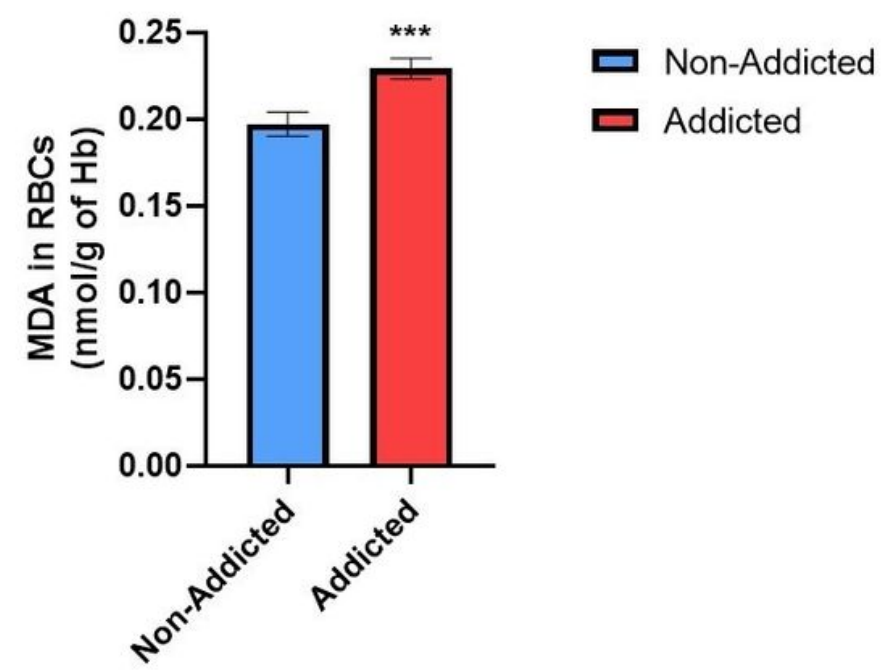

$4 a$

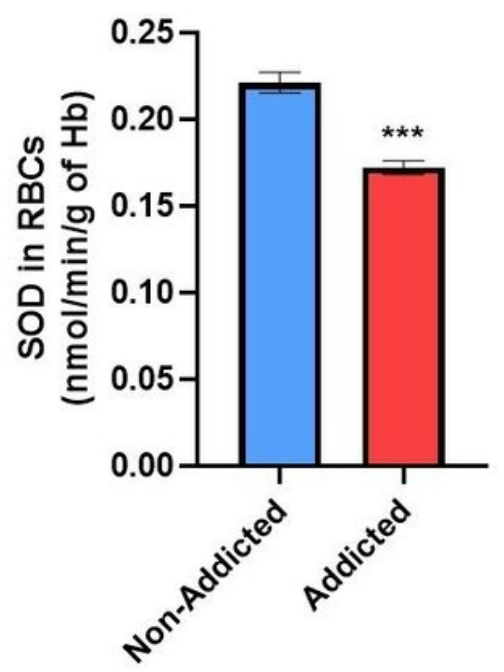

$\square$ Non-Addicted

$\square$ Addicted

$4 \mathrm{~b}$

\section{Figure 4}

4.a: Effects of nicotine-addiction on MDA levels in the RBCs of addicted and non-addicted respondents. MDA levels (markers of oxidative stress) in the RBCs of nicotine-addicted were measured significantly higher $(p=0.0006)$.

4.b: Effects of nicotine addiction on the antioxidant activity of superoxide dismutase (SOD) in the RBCs. Comparatively, low/reduced activity of SOD was assessed in the nicotine-addicted respondents that were found statistically significant $(p=0.0001)$. 


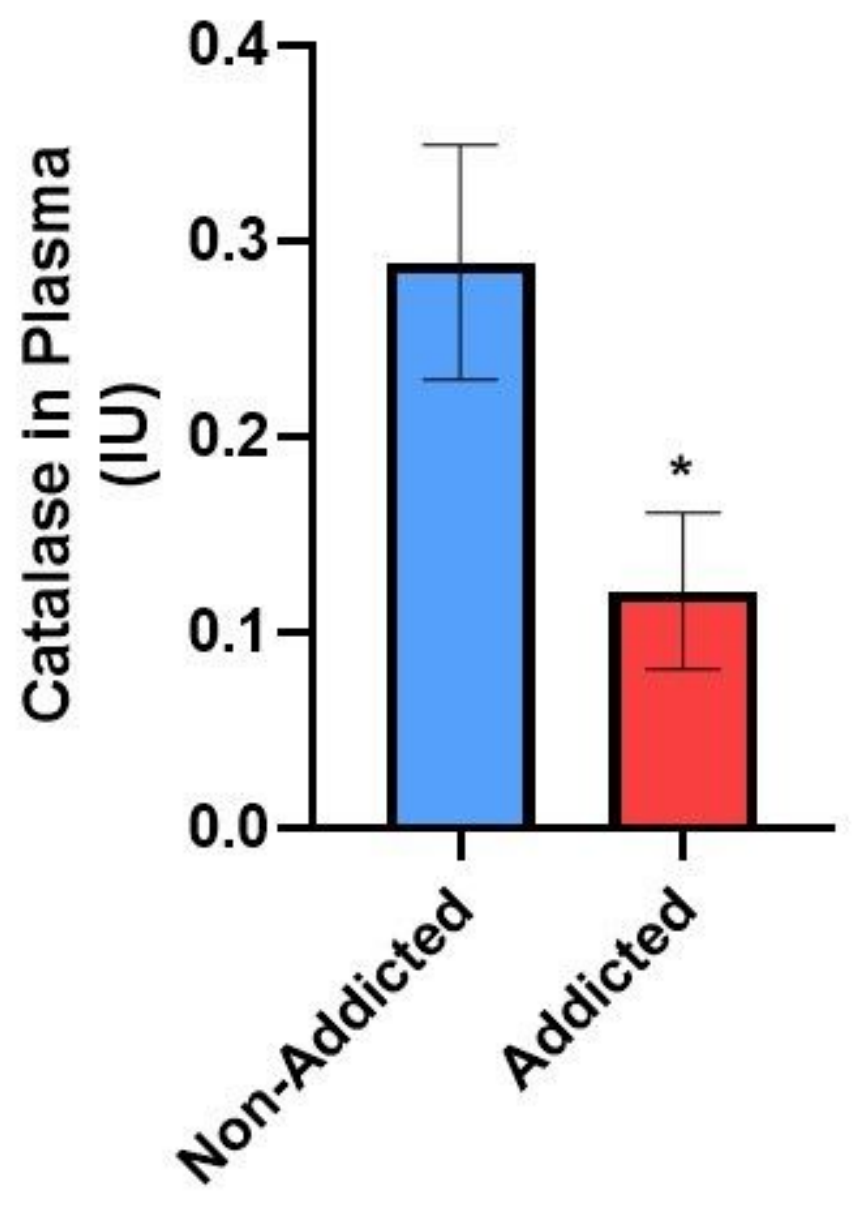

$\square$ Non-Addicted

$\square$ Addicted

\section{Figure 5}

Effects of nicotine addiction on the antioxidant activity of plasma Catalase. Diminished Catalase activity was measured in the addicted group whereas non-addicted respondents expressed high Catalase efficacy that was found statistically significant $(p=0.02)$.

\section{Supplementary Files}

This is a list of supplementary files associated with this preprint. Click to download.

- SupplementaryMaterials.docx 